\title{
Photochemical behaviour of activated carbons under UV irradiation
}

Leticia F. Velasco ${ }^{1,2}$, Isabel M. Fonseca ${ }^{2}$, José B. Parra ${ }^{1}$, Joao C. Lima ${ }^{2}$, Conchi Ania ${ }^{1 *}$

${ }^{1}$ Instituto Nacional del Carbón, INCAR-CSIC, Apdo. 73, 33080 Oviedo, Spain

${ }^{2}$ REQUIMTE/CQFB, Dpt. Química, Faculdade de Ciências e Tecnologia, Universidade Nova de Lisboa, 2829-516 Lisboa, Portugal

\section{Abstract}

A series of activated carbons was used to investigate the photochemical behaviour of carbons under UV light as catalysts in the photo-oxidation of phenol in the absence of semiconductor additives. Conventional photocatalytic tests showed an improved photo-oxidation in the presence of activated carbons, beyond the so-called synergistic effect reported in the literature for carbon/titania composites. A novel approach based on UV irradiation of carbons preloaded with phenol was used to demonstrate the anomalous photochemical response of carbon materials towards phenol degradation. Analysis of the catalytic reaction from a different standpoint (inside the carbonaceous matrix) demonstrated the catalytic activity of certain carbon materials for phenol photodegradation, without considering photolytic breakdown and adsorption kinetics. The pseudo photochemical quantum yield of several activated carbons was higher than that of photolysis under the same conditions; the nature of the degradation intermediates was also modified in the presence of the carbon materials. Moreover, the degradation of the adsorbed fraction retained inside the pore structure of the carbons has been demonstrated. Our results suggest the occurrence of carbon-photon interactions which could be propagated through the graphene sheets of the materials, and could reach the adsorbed molecules inside the pores. 


\section{Introduction}

The development of advanced oxidation processes for wastewater remediation has received much attention in the last years; particularly extensive research is being carried out on the synthesis of more efficient photocatalysts to promote the degradation of recalcitrant pollutants (and ideally the complete mineralization). Among the catalysts, titanium oxide -a direct wideband gap semiconductor (i.e. $3.20 \mathrm{eV}$ )- has been extensively studied since it is non-toxic, photostable, cheap and very efficient under ultraviolet light (UV) [1-3]. The synthesis of porous titania, or its immobilization on porous supports has received much attention recently, because of the limitations of titania powders related to their recovery that prevent the large scale implementation in the wastewater remediation arena [4-8]. In this regard, extensive work has been carried out on the improved photocatalytic activity of semiconductors immobilized on carbon supports, carbon-coated titania or carbon doped titania [9-12].

Carbons are strong light absorbing materials, despite of which they have been successfully used as support of photoactive species [13-16]. Although it is hard to understand how light could penetrate the carbon particles to reach the immobilized photocatalyst, carbon-titania composites have shown quite high efficiencies for the photodegradation of a variety of pollutants [17-19]. For instance, the presence of activated carbons and carbon nanotubes seems to change the photocatalytic activity of $\mathrm{TiO}_{2}$ towards the degradation of organic pollutants beyond the so-called "synergistic" effect (i.e., improved photodegradation rates) $[13-16]$

In this regards, we have recently reported the anomalous response of an activated carbon towards phenol degradation in aqueous medium [20]. Direct UV irradiation of the solution in the presence of the carbon material and the absence of any other photoactive species showed that beyond phenol degradation by photolysis, the carbon material improved the photo- 
oxidation rate of phenol, compared to bare or immobilized titania. The results suggested the occurrence of interactions between UV light and carbon particles.

To discriminate whether this behaviour is a singular characteristic of that particular activated carbon or rather an intrinsic property of certain carbon materials, we have explored the behaviour of several porous activated carbons obtained from different precursors and exhibiting varied porosity and composition when exposed to UV irradiation. The aim of this work is to unambiguously demonstrate that under UV irradiation, carbon materials are capable of promoting the degradation of organic pollutants in aqueous medium (in the absence of semiconductor additives).

\section{Experimental}

\subsection{Materials}

A series of porous activated carbons from different origins were selected for this study. The main physicochemical properties are compiled in Table 1. Briefly they are as follows: Q (bituminous coal, steam activation), $\mathrm{PC}$ (plastic waste derived, $\mathrm{CO}_{2}$ activation), $\mathrm{CV}$ (woodbased, $\mathrm{H}_{3} \mathrm{PO}_{4}$ activation), FY5 (Calgon, bituminous coal based, steam activation) and BKK (bituminous coal, physical activation). The procedure for the preparation of PC has been described elsewhere [21].

\subsection{Photolysis and photodegradation experiments}

Dark adsorption and phenol photolysis and photodegradation experiments were performed under the same experimental conditions, by means of kinetics studies from batch experiments at room temperature. Briefly, for adsorption in dark conditions about $1 \mathrm{~g} \mathrm{~L}^{-1}$ of adsorbent was placed in dark glass flasks containing $400 \mathrm{~mL}$ of phenol solution (in distilled non buffered water) of initial concentration $100 \mathrm{mg} \mathrm{L}^{-1}$. The suspensions were vigorously stirred (600 rpm) and small aliquots of the solution $(\sim 1.5 \mathrm{~mL})$ were taken out at predetermined time intervals 
and analyzed by reverse-phase HPLC (Spherisorb C18 column $125 \mathrm{~mm}$ x $4 \mathrm{~mm}$ ), using methanol-water mixture (5:95) as mobile phase, using a photodiode array detector. The samples were previously filtered using regenerated cellulose filter having mean pore size of $0.45 \mu \mathrm{m}$.

Table 1. Main physicochemical characteristics of the selected activated carbons obtained from gas adsorption and elemental analysis.

\begin{tabular}{|c|c|c|c|c|c|}
\hline & $\mathbf{Q}$ & CV & FY5 & BKK & PC \\
\hline SBET $\left[\mathrm{m}^{2} \mathrm{~g}-1\right]$ & 1033 & 1280 & 799 & 961 & 1357 \\
\hline VTOTAL $\left[\mathrm{cm}^{3} \mathrm{~g}^{-1}\right]^{\mathrm{a}}$ & 0.519 & 1.057 & 0.346 & 0.566 & 0.601 \\
\hline$V_{\text {MICROPORES }}\left[\mathrm{cm}^{3} \mathrm{~g}^{-1}\right]^{\mathrm{b}}$ & 0.316 & 0.314 & 0.256 & 0.292 & 0.453 \\
\hline VMESOPORES $\left[\mathrm{cm}^{3} \mathrm{~g}^{-1}\right]^{\mathrm{b}}$ & 0.089 & 0.517 & 0.027 & 0.058 & 0.044 \\
\hline $\mathrm{Wo}, \mathrm{CO}_{2}(\mathrm{DR})\left[\mathrm{cm}^{3} \mathrm{~g}^{-1}\right]^{\mathrm{c}}$ & 0.185 & 0.146 & 0.265 & 0.220 & 0.268 \\
\hline$C[w t . \%]^{d}$ & 96.6 & 87.1 & 96.2 & 94.0 & 99.2 \\
\hline$H[w t . \%]^{d}$ & 0.6 & 2.8 & 0.8 & 0.3 & 0.3 \\
\hline$N[w t . \%]^{d}$ & 0.7 & 0.3 & 0.3 & 0.8 & 0 \\
\hline$O{\text { [wt. } \%]^{d}}^{d}$ & 2.1 & 9.8 & 2.7 & 4.7 & 0.6 \\
\hline pHPZC & 8.9 & 2.2 & 9.0 & 8.5 & 10.9 \\
\hline
\end{tabular}

a evaluated at $p /$ po 0.99

b evaluated from DFT method applied to $N_{2}$ adsorption data

' evaluated from $\mathrm{DR}$ method applied to $\mathrm{CO}_{2}$ adsorption data

${ }^{\mathrm{d}}$ DAF basis

Photodegradation experiments were carried out in a photo-reactor of $400 \mathrm{~mL}$ capacity. The UV irradiation source was provided by a high pressure mercury lamp $(125 \mathrm{~W})$, vertically suspended in a cylindrical, double-walled quartz jacket cooled by flowing water, immersed in the solution. The water cell was used to control the temperature during the experiments, preventing any overheating of the suspension due to the irradiation. At regular intervals, aliquots of the solution were extracted and analyzed. The corresponding extract yield for each pure compound was evaluated. The photolysis (non-catalyzed degradation reaction) of phenol was performed through the irradiation of an aqueous solution of phenol in the absence of catalyst. All the experiments were done in triplicate and demonstrated to be reproducible; reported data represent the average values. 
Prior to the experiments the photon flux arriving at the solution was measured through ferrioxalate actinometry [22]. The photochemical quantum yield of phenol photolysis $(\phi)$ defined by IUPAC as the ratio between the number of mol reacted, $\Delta \mathrm{N}$, per mole of photons absorbed $\left(I_{A} \Delta t\right)$ - was evaluated from the slope of the relation between the mol of pollutant degraded vs the irradiation time with the equation [23]:

$\Delta N=\phi I_{A} \Delta t$

where $I_{A}$ is the photon flux absorbed by the sample, evaluated from the product of the incident photon flux Io, determined by actinometry, and the integrated absorption fraction $\mathrm{F}_{\mathrm{S}}$ over the wavelength range used in the experiment. The photochemical quantum yield was evaluated in solution from the slope of the plot of the number of mol of degraded phenol per incident photon flux vs the irradiation time.

\subsection{Photodegradation experiments on pre-loaded samples}

Carbon samples were loaded by putting in contact an adequate amount of the activated carbon with a diluted phenol solution $\left(40 \mathrm{mg} \mathrm{L}^{-1}\right)$, until all phenol is adsorbed (no phenol was detected in solution). Subsequently the samples were irradiated for 20 minutes using the photo-reactor described above. After irradiation, the carbon samples were extracted with ethanol and both the alcoholic extracts and the remaining aqueous solution were analyzed by HPLC. The corresponding extract yield for each pure compound was evaluated.

\subsection{Characterization of the carbon catalysts}

The nanotexture of the activated carbons was characterized by $\mathrm{N}_{2}$ (ASAP 2010, Micromeritics) adsorption isotherms at $-196^{\circ} \mathrm{C}$. Before the experiments, the samples were outgassed under vacuum (ca. $10^{-3}$ torr) at $120^{\circ} \mathrm{C}$ overnight. The isotherms were used to calculate the specific surface area, $\mathrm{S}_{\mathrm{BET}}$, total pore volume, $\mathrm{V}_{\mathrm{T}}$, and pore size distribution 
using the density functional theory (DFT) assuming a slit-shape pore geometry. Additionally, the distribution of pores smaller than $0.7 \mathrm{~nm}$ (narrow micropores) was assessed from $\mathrm{CO}_{2}$ adsorption isotherms at $0{ }^{\circ} \mathrm{C}$ (Tristar 3000, Micromeritics) using the DR formulism. The activated carbons were further characterized by elemental analysis (LECO CHNS-932 and LECO VTF-900 automatic analyzers).

A custom made device for TPD-MS was also used to evaluate the surface chemistry of the activated carbons. The samples were heated in a silica fused reactor up to $900{ }^{\circ} \mathrm{C}$ at a heating rate of $10^{\circ} \mathrm{C} \mathrm{min}^{-1}$. The analysis was done under high vacuum conditions (below $10^{-5} \mathrm{mbar}$ ) and the gas phase was continuously monitored by a mass spectrometer. The amount of CO and $\mathrm{CO}_{2}$ evolved during the TPD experiments were quantified.

\section{Results and discussion}

\subsection{Characterization of the activated carbons}

A detailed characterization of the porosity and surface chemistry of the selected activated carbons is shown in Table 1 and Figures 1 and 2. The analysis of the data obtained from the gas adsorption isotherms indicates that all carbons, with the exception of $\mathrm{CV}$, show type I isotherms according to the IUPAC classification [24], characteristic of microporous materials. For $\mathrm{CV}$, the $\mathrm{N}_{2}$ adsorption isotherm shows a hybrid I/IV character, with a broad knee at low relative pressures and a marked hysteresis loop (type H4) above 0.5. Theses features indicate that along with a microporous structure comprised of wide micropores, this sample exhibits a well developed mesoporosity. This was confirmed by the pore volumes obtained by the DFT method (Table 1).

Regarding surface chemistry, the studied activated carbons present varied hydrophobic/hydrophilic nature as shown by data compiled in Table 1. For instance, large amounts of $\mathrm{CO}$ and $\mathrm{CO}_{2}$-releasing functionalities were obtained for carbons $\mathrm{CV}, \mathrm{BKK}$ and 
FY5, assigned to carboxylic acids and anhydrides (decomposing as $\mathrm{CO}_{2}$ below $500^{\circ} \mathrm{C}$ ), lactones, phenols and carbonyl/quinone-type groups (decomposing as $\mathrm{CO}$ and $\mathrm{CO}_{2}$ above $\left.600^{\circ} \mathrm{C}\right)[25]$.
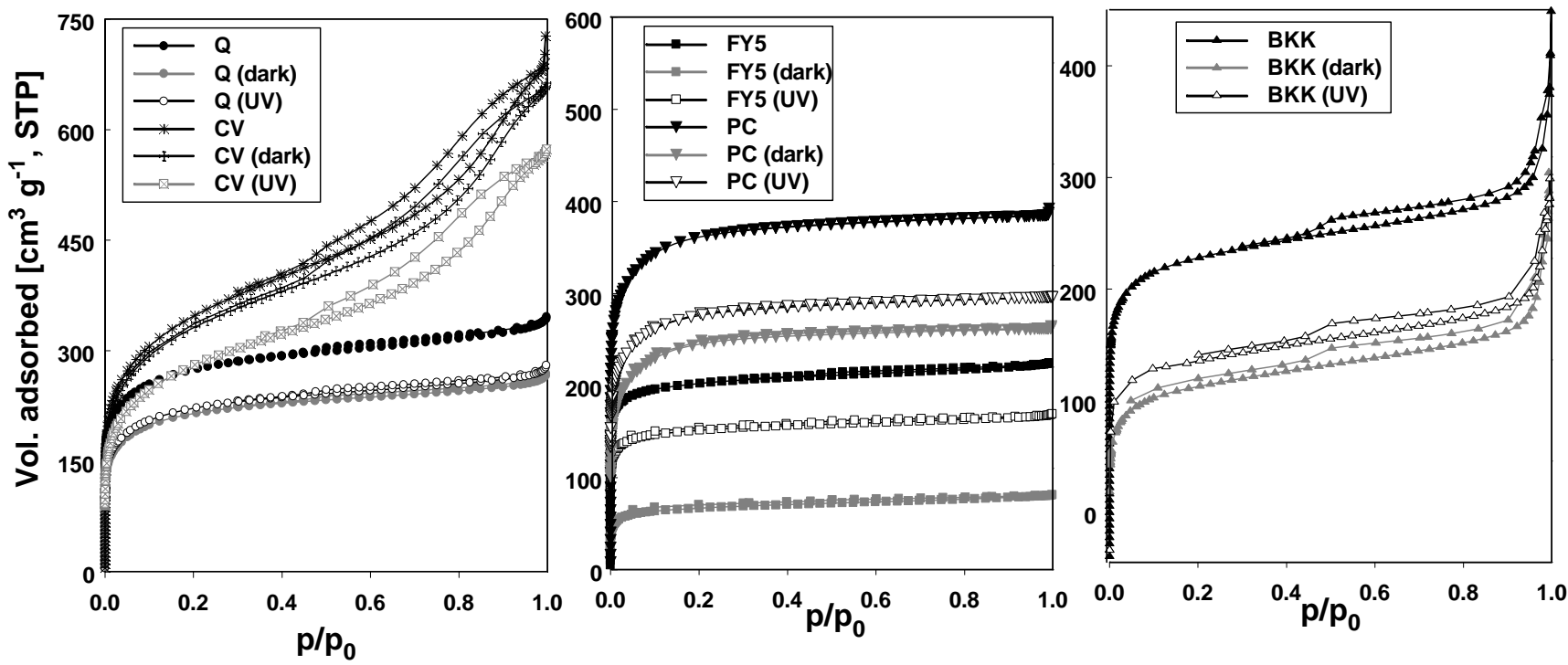

Figure 1. $\mathrm{N}_{2}$ adsorption isotherms at $-196^{\circ} \mathrm{C}$ of the as-received carbon materials, and after phenol removal under dark conditions (dark series) and UV irradiation (UV series).

The large amount of gases (both $\mathrm{CO}$ and $\mathrm{CO}_{2}$ ) released for $\mathrm{CV}$ carbon is in good agreement with the acidic nature of this carbon (Table 1) shown by its $\mathrm{pH}_{\mathrm{PZC}}$. In contrast, the low density of surface functional groups for Q and PC carbons confirmed their high hydrophobic character. The $\mathrm{CO}_{2}$ profiles of carbon BKK show two sharp and narrow peaks between 400 and $600^{\circ} \mathrm{C}$, which should be attributed to the decomposition of inorganic compounds present in the mineral matter (ca. ash content $3.5 \mathrm{wt} . \%$ ) rather than to oxygen-containing functional groups [26]. 

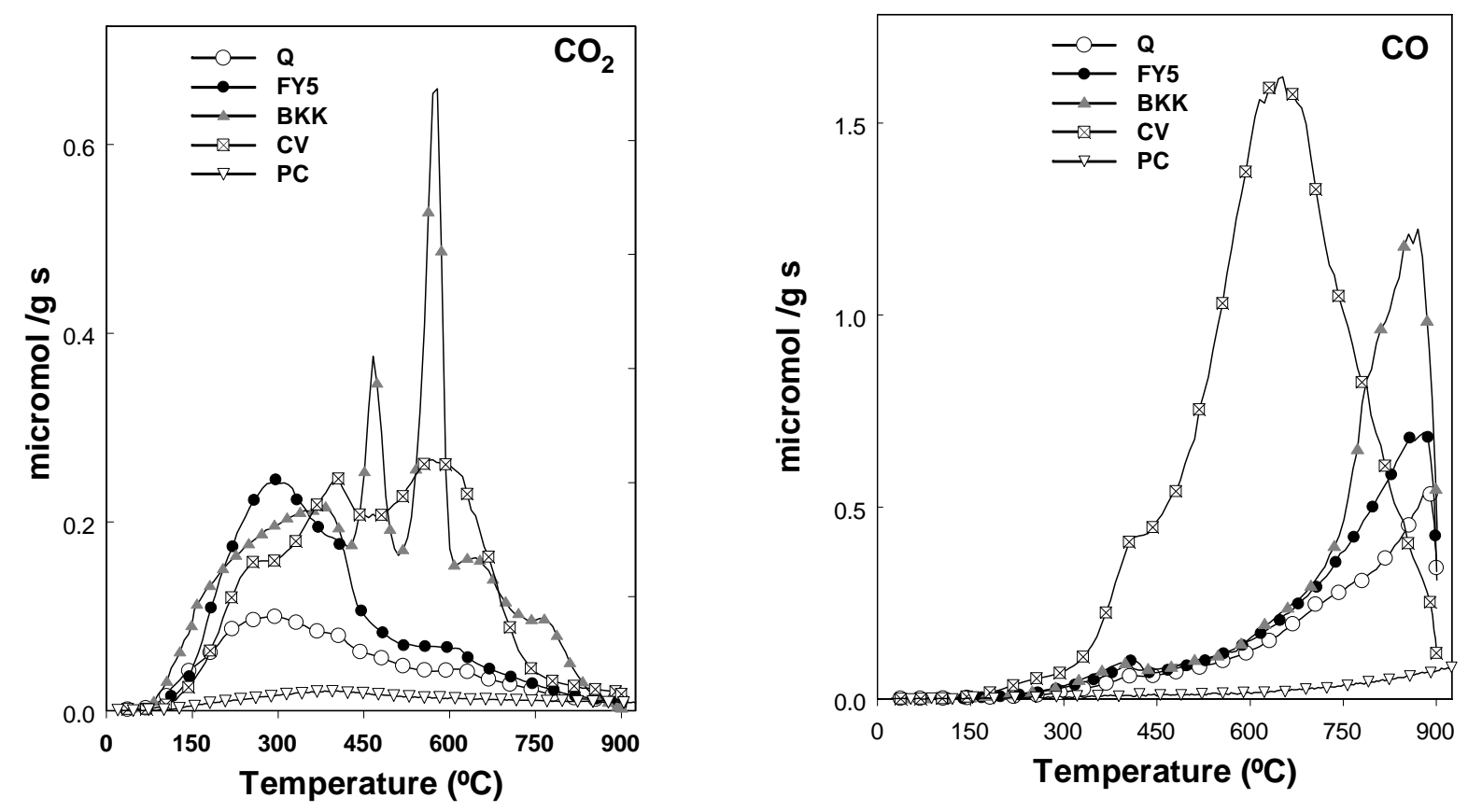

Figure 2. $\mathrm{CO}$ and $\mathrm{CO}_{2}$ profiles of the investigated carbons evaluated by TPD-MS.

\subsection{Phenol photodegradation in classical systems}

Given the porous nature of the investigated carbons, the amount of phenol (and its degradation intermediates) retained in the porous network of the carbons cannot be neglected. Consequently, the experiments were also carried out in the absence of UV irradiation (dark conditions) to differentiate between the adsorptive process and photo-oxidation under UV light (where both adsorption and degradation occur simultaneously). The performance of the studied carbons evaluated by kinetic measurements is shown in Figure 3. Data corresponding to phenol photolysis (non-catalyzed reaction) due to phenol degradation by direct UV irradiation of the solution has also been included for comparison reasons.

First of all, it has to be mentioned that phenol degradation was not observed in the absence of UV irradiation: neither in solution nor in the presence of carbon. Thus, the decay in phenol concentration during experiments labelled as dark conditions is exclusively due to the retention on the porosity of the catalysts. This was further confirmed by the HPLC analysis of 
the species in solution and also the compounds retained in the carbons porosity -previous extraction of the adsorbed phase in ethanol-. Moreover the mass balance between both phases after the adsorption experiments matched completely. This is, phenol was the only compound detected in dark conditions.
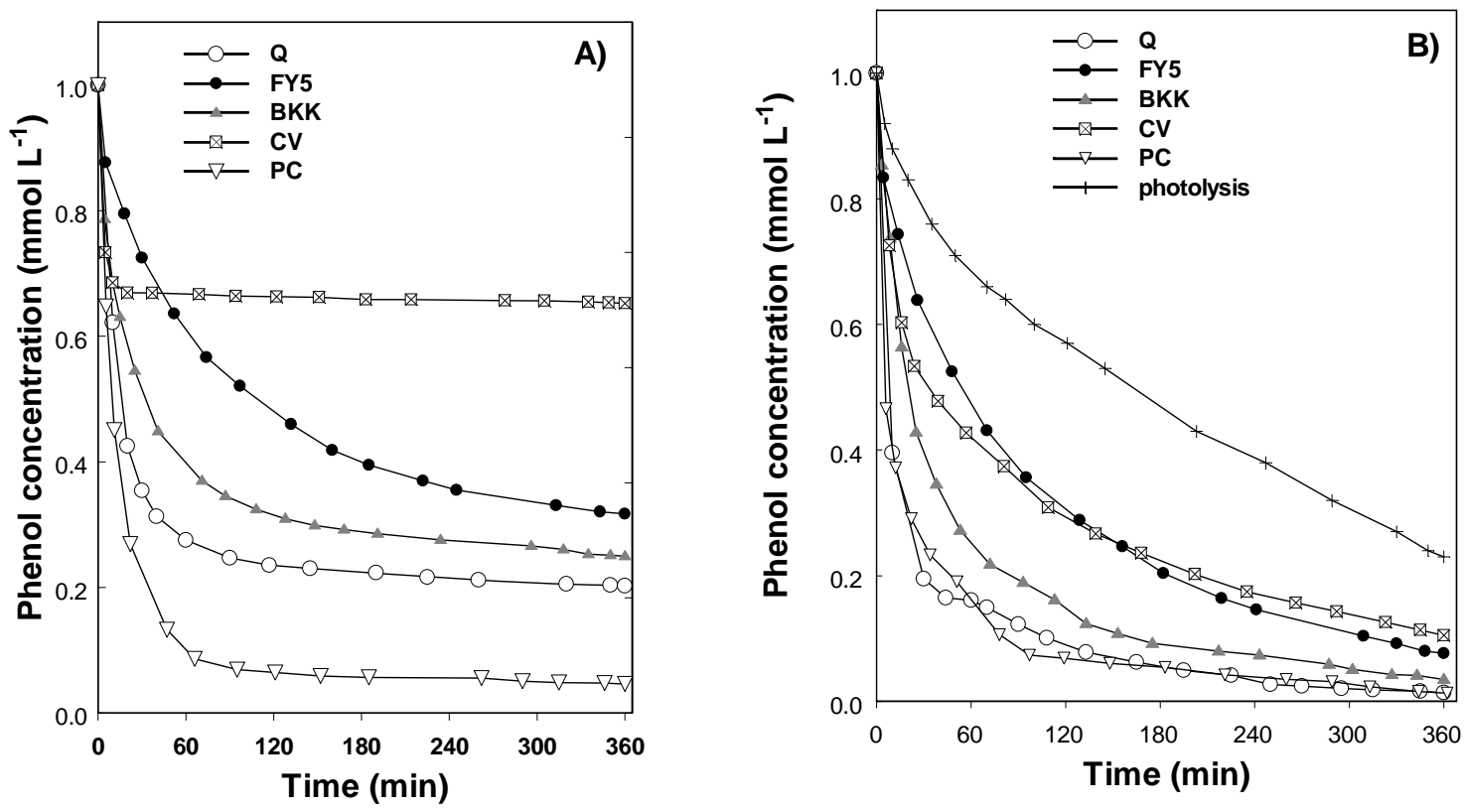

Figure 3. Phenol concentration decay curves on the investigated photocatalysts after dark adsorption (A) and UV irradiation (B).

The amount of phenol adsorbed during the dark experiments was strongly dependent on the physicochemical characteristics of the carbon materials. This was in good agreement with expectations based on the general knowledge about the adsorption mechanisms of phenol on activated carbons with varied chemical and porous features [27-29]. For instance, the largest amount adsorbed (after 6 hours) corresponded to carbons Q and PC which displayed high micropore volumes and hydrophobic character (Table 1), whereas the low uptake obtained for sample CV despite its high surface area and porous features accounts for its acidic nature [29]. 
In the case of photolysis, phenol degraded is due to direct interaction with UV light [30], being catechol (CAT), hydroquinone (HY) and benzoquinone (BZ) the main degradation intermediates detected (Figure 4). Along with the aromatic sub-products shown in Figure 4, short alkyl-chain organic acids (including formic acid and maleic acid among most representatives) were also detected in the solution (ca. $80 \%$ ). However, the analysis of the Total Organic Carbon (TOC) content rendered $73.5 \mathrm{mg} \mathrm{C} / \mathrm{L}$ after UV irradiation for the photolysis (Table 2), indicating that under these conditions (i.e., lamp characteristics, phenol initial concentration, solution $\mathrm{pH}$ ) conversion of phenol into $\mathrm{CO}_{2}+\mathrm{H}_{2} \mathrm{O}$ (mineralization) accounted for only $3 \%$ by direct UV irradiation of the solution.

Table 2. TOC values $(\mathrm{mg} \mathrm{C} / \mathrm{L})$ in solution after 6 hours (initial TOC values were $76 \mathrm{mg} \mathrm{C} / \mathrm{L}$ in all the cases) and relative abundance of aromatic and short alkyl chain organic acid intermediates detected in solution (\%).

\begin{tabular}{cccccccc}
\hline & & Photolysis & Q & CV & FY5 BKK & PC \\
\hline $\begin{array}{c}\text { TOC values } \\
(\mathbf{m g ~ C / L )}\end{array}$ & UV light & 73.5 & 10.2 & 21.8 & 22.3 & 17 & 15.8 \\
& Dark Conditions & --- & 15.7 & 48.9 & 24 & 18.7 & 3.5 \\
\hline $\begin{array}{c}\text { Relative } \\
\text { abundance } \\
(\%)\end{array}$ & Aromatics & 24 & 12 & 39 & 30 & 18 & 19 \\
\hline
\end{tabular}

It has to be considered that photolysis is measured in a catalyst-free solution, for which dispersion of the UV light by interaction with suspended solids (catalysts particles) is not expected. Thus, the incident light is only utilized on the direct breakdown of the pollutant. The photochemical quantum yield for phenol degradation $(\phi)$ in the photolytic reaction determined from the plot of the number of mol of degraded phenol per incident photon flux vs the irradiation time- yielded $\phi=16 \mathrm{mmol} /$ Einstein, which matches with values reported in the 
literature for this aromatic compound using different UV sources and solution conditions [31-33].
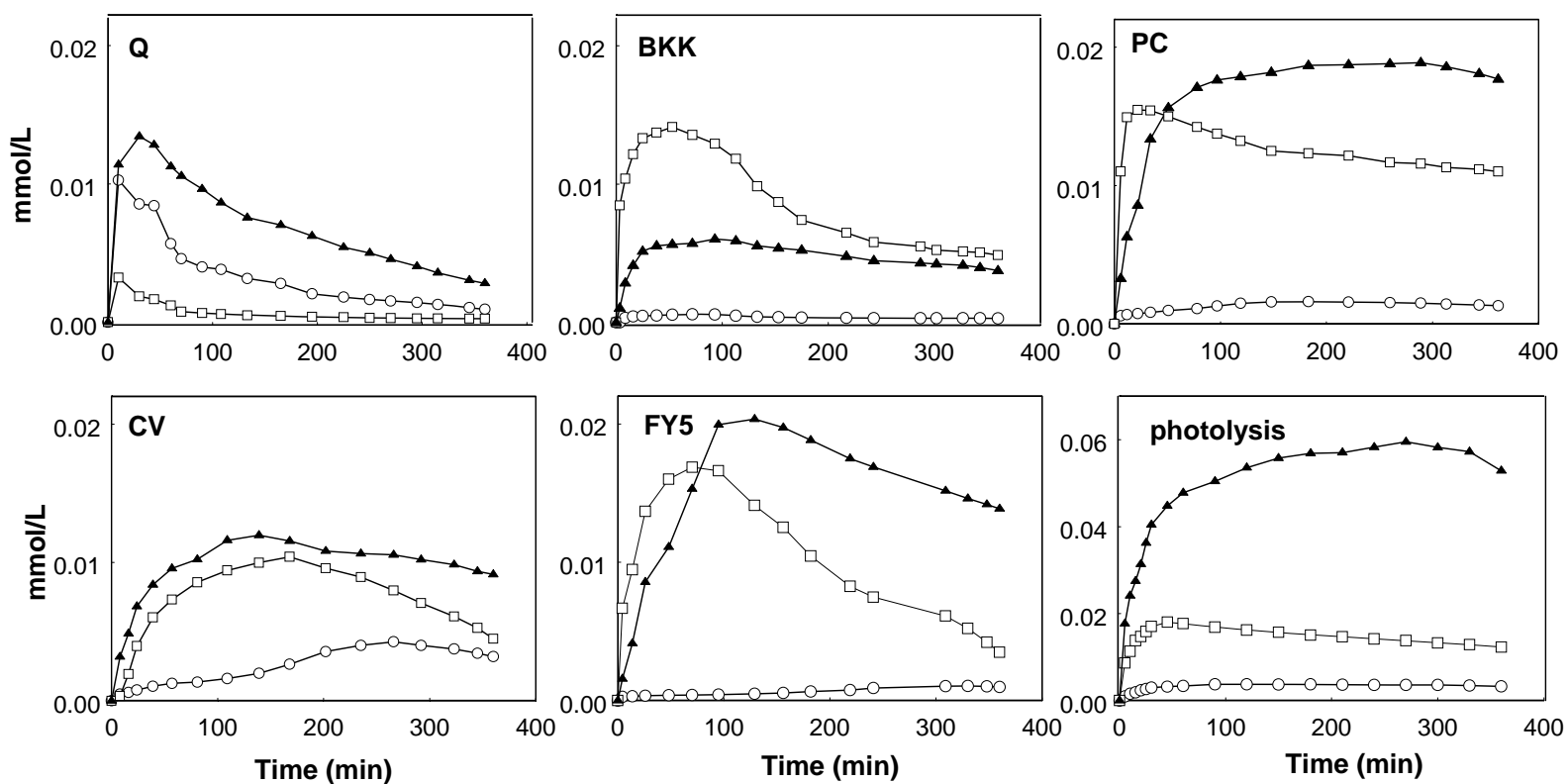

Figure 4. Evolution of the concentration of phenol degradation intermediates upon UV irradiation of the different investigated photocatalysts. BZ (squares), HY (circles) and CAT (triangles).

In the presence of the activated carbons, the photocatalytic degradation becomes more complex as physical adsorption and photo-oxidation coexist. Under these conditions, estimation of the photochemical efficiency is a hard task due to the difficulties associated to the evaluation of the accurate incident photon flux (due to the fraction of light absorbed by the carbon and light scattering by the catalyst particles suspended in solution). Anyhow it seems reasonable to consider that this would certainly be much lower than that in the photolytic reaction (where neither light scattering nor catalyst absorption occur). At the same time, UV light is a priori not expected to interact with the adsorbed molecules retained on the porosity of the carbons, and so degradation of the adsorbed fraction would not be expected (either for 
phenol or any of its degradation intermediates). Thus, the concentration of phenol molecules in solution is expected to decrease due to adsorption (the adsorbed fraction increasing with time) and photolysis.

The rate of phenol disappearance when the activated carbons are used as photocatalysts is shown in Figure 3, compared to the adsorption rate in dark conditions. For all the activated carbons the initial rate of phenol adsorption is very fast and most of the amount adsorbed is accomplished within the first 60 minutes. Upon UV irradiation the overall rate of phenol disappearance increased remarkably for all the carbons, which was somehow expected due to the simultaneity of the adsorption and photo-oxidation processes. This trend was more evident at the initial stage of the reaction (short times), and particularly more evident for carbon $\mathrm{CV}$ where the phenol removal increased from $35 \%$ in dark conditions (adsorption) to $90 \%$ under UV light. This observation was rather surprising since carbon CV has an acidic nature, and thus the retention of phenol (and its degradation intermediates) is not favoured [27, 28]. To identify if the behaviour of this acidic carbon was linked to any likely modification in its surface chemistry induced by the UV irradiation, a blank experiment was carried out in the absence of phenol (UV irradiation of the activated carbon in water). An exhaustive characterization (gas adsorption, thermal and elemental analysis) revealed that neither the textural nor the physicochemical properties of CV carbon were modified upon UV irradiation in the blank experiments (the same result was obtained for all the studied carbons). Thus the improved removal rate under UV light might be attributed to the acidic nature of CV carbon. In the case of carbon FY5, the kinetics of phenol disappearance (photo-oxidation + adsorption) under UV light proceeded slowly. This trend was also observed for the dark experiments, and thus could be explained by the narrow distribution of micropore sizes of this sample (according the $\mathrm{N}_{2}$ adsorption data). 
After 6 hours of irradiation, phenol was almost completely removed from the solution although some other intermediates were visible in the solution in detectable quantities (below $\left.0.5 \mathrm{mmol} \mathrm{L}^{-1}\right)$. The evolution of the intermediates concentration in the solution with the irradiation time is shown in Figure 4, while the TOC values measured after 6 hours are compiled in Table 2. The solution TOC values decreased after 6 hours irradiation with the exception of carbon PC, which value was about 5 times larger than the corresponding value obtained at dark conditions (where only adsorption occurs).

Speciation of the intermediates found in the solution indicated the predominance of organic acids (Table 2). What is more interestingly inferred is that relative abundance of the degradation intermediates detected in solution was not the same for all the carbons (Figure 4) and seemed to be related to their physicochemical features. Outstanding differences were also noticeable compared to photolysis. For instance, the amount of HY at short times for carbon Q largely exceeded that of photolysis. These results suggest that the activated carbons must play a role in the photo-oxidation reaction. The modification of phenol photodegradation pathway has already been postulated when the carbon is used as support of a semiconductor (typically $\left.\mathrm{TiO}_{2}\right)[15,16]$.

It is interesting to point out the differences concerning the nature of the photodegradation intermediates observed for Q, PC and FY5 carbons; in spite these materials display a rather similar basic nature (see $\mathrm{pH}_{\mathrm{PZC}}$ in Table 1), small amounts of $\mathrm{BZ}$ were obtained even from the early stages of the photocatalytic reaction when Q is used as catalyst, as opposed to carbons FY5 and PC. The opposite trend was obtained for HY with these three carbons. The concentration of BZ decreases gradually with time, whereas for CAT and HY this trend was not observed. In the former the concentration rather stabilized at large times (with the exception of carbon Q), where for the latter, there is an increase after 3 hours of irradiation in the case of carbons CV, FY5 and PC. At converse for the acidic carbon CV, the amount of 
HY detected in solution increased after 2-3 hours of irradiation, showing a concentration peak at about $240 \mathrm{~min}$ ). This is surprising bearing in mind that, due the porous nature of the activated carbons, these intermediates are expected to adsorb in the carbon porosity and thus the amount detected in solution should be larger for photolysis. In all cases, the high concentrations found for CAT (dominant for all the carbons but BKK) anticipate the preferential photo-oxidation of phenol through the cathecol pathway in the presence of activated carbons. Similar observations have been reported when carbon materials are used as catalyst supports $[13-16,20]$. This degradation pathway is considered more advantageous for the complete mineralization of phenol than conversion to $\mathrm{BZ}$ and $\mathrm{HY}[34,35]$, that proceeds through a complex mechanism involving a larger number of intermediates (organic acids). The high concentration of organic acids detected for the carbons PC, FY5 and CV (which also displayed higher amounts BZ and HY) supports this evidence.

To discriminate whether if the activated carbons have any role on the photo-oxidation process itself, or if the decrease in phenol concentration is due to simultaneous adsorption and photolytic reaction, the results have been analysed from different viewpoints. When UV light is applied, the solution (initially single component) becomes a complex multicomponent matrix due to the photolytic breakdown of phenol into hydroxylated phenols and other derivatives, as mentioned above. At the same time, these newly formed compounds can i) undergo further photodegradation and ii) be adsorbed in the porosity of the activated carbons. The extent of adsorption on the carbons porosity will be controlled by the affinity of each compound towards the carbons, and competitive adsorption effects [36, 37]. Based on the similar chemical structure between phenol and its aromatic photo-oxidation intermediates (i.e., CAT, BZ, HY and so forth), it seems reasonable to expect similarities in their affinity (i.e., adsorptive performance) towards the carbons. The retention of these compounds from single component solutions on the studied carbons confirmed this hypothesis. Indeed, for all 
the degradation intermediates the adsorption kinetics and amount adsorbed under dark conditions were very similar to those obtained for phenol, even for the acidic carbon (data not shown). Moreover, thermal analysis of the exhausted carbons also confirmed that these compounds occupy the same adsorption sites in the activate carbons. Thus, a competitive adsorption scenario between phenol and these intermediates for the active sites would be expected in the presence of the activated carbons.

In contrast, the organic acids show smaller affinity for the activated carbons [38], with much lower adsorption capacities and slow kinetics from single component solution. Thus, although preferential adsorption of the aromatic compounds over the organic acids occurs [36], at this point it has to be reminded that all the experiments have been carried out using diluted phenol solutions. Based on previous studies $[28,29]$ and considering the porous features of the activated carbons (Table 1), the initial concentration used is far below the maximum adsorption capacity of the carbons. In other words, the porous network of the activated carbons is not saturated, and active sites of adsorption are available at any time. Consequently, phenol and its photo-oxidation intermediates should be retained on the porosity of the activated carbons during the irradiation experiments.

Moreover, UV light is not a priori expected to reach the adsorbed fraction (inside the carbons porosity) for which no desorption of the retained compounds should occur. So if photolytic breakdown of phenol is the only reaction occurring and carbons are considered as non photoactive materials, the enhancement in the overall phenol degradation efficiency (so-called synergistic effect when $\mathrm{C} / \mathrm{Ti}$ composites are used) $[15,16]$ would be exclusively governed by the adsorption rate on the carbons porosity.

Nevertheless, our results contest this hypothesis, which cannot account for the different photochemical behaviour (rate and intermediates speciation) obtained for activated carbons with similar porosity and varied surface chemistry. This is the case, for instance, of carbons Q 
and PC that both have similar phenol adsorption kinetics in dark conditions (Figure 3) and display a basic character and microporous structure. However, although the overall phenol removal under UV light seems to be similar, the evolution of intermediates detected in solution is very different (Figure 4). The TOC values (Table 2) also followed a different trend, and in the case of PC carbon the obtained values increased after UV irradiation (as discussed above). All these results point out to a specific role of the activated carbons on the photo-oxidation reaction.

On the other hand, this eventual photocatalytic response of activated carbons under UV irradiation could just be considered as a consequence of a confinement effect of the compounds in the porosity of the activated carbons (i.e, concentration effect on photolysis), the former exclusively acting as porous supports. This hypothesis should not be disregarded at first as the photolysis yield increases with the initial concentration of the pollutant/phenol in solution (data not shown). To clarify this issue, we have characterized the activated carbons after the UV experiments by thermal and gas adsorption. The DTG profiles after the UV irradiation were similar to those of the corresponding dark experiments for all the studied activated carbons (data not shown), with a single peak between 200 and $500{ }^{\circ} \mathrm{C}$ attributed to the desorption of phenol and/or degradation intermediates [28]. Moreover the intensity of this peak was about the same for both experiments, with the exception of carbon FY5. Analogously, the $\mathrm{N}_{2}$ adsorption isotherms revealed a decrease in the porosity of the carbons after phenol exposure, compared to the pristine samples (Figure 1). Although this was observed for both dark and UV experiments, there are some important differences to be mentioned. Surprisingly, for all the samples with the exception of $\mathrm{CV}$, the decrease in the $\mathrm{N}_{2}$ adsorption isotherm is smaller after UV irradiation, being this trend more evident for carbon FY5. Since UV light brought about an increase in the phenol removal (also confirmed by the decrease in TOC values in Table 2), one would have expected just the opposite trend as the 
removed phenol is retained on the carbons porosity; particularly for those carbons where this effect was more remarkable, such as BKK and FY5.

The observed fall in the textural properties (Figure 1) indicates that the concentration of species adsorbed on the porosity of the carbons is lower after UV irradiation than after dark condition experiments (with exception of $\mathrm{CV}$ ). In the case of $\mathrm{CV}$, the decrease in the porous features accounts for $19 \%$ after irradiation, vs $5 \%$ for adsorption. The different behaviour of this acidic carbon can be attributed to the low phenol removal efficiency under dark conditions (35\%), which is largely increased when UV light is applied (90\%). Consequently, the amount of species adsorbed after UV irradiation would be expected much larger. Based on these results, there seems to be a mass unbalance between the amount of phenol detected in solution and that retained on the carbon porosity during UV illumination.

All these results suggests several possible scenarios on which (1) adsorption of the photooxidation intermediates is hindered or suppressed; (2) intermediates remain (rather than being adsorbed) or are released to the solution; (3) a partial mineralization of phenol and/or the compounds could be occurring if UV light interacts with the adsorbed compounds retained in the inner porosity.

The desorption of the intermediates once adsorbed (scenario 2) is unlikely to happen based on their favourable thermodynamic features for adsorption on the activated carbons and their behaviour from single component solutions based on our own studies (data not shown) and the literature $[36,38]$. On the other hand, the large TOC values (Table 2) measured in solution for carbons FY5 and BKK confirm that the intermediates remain in solution, at least after 6 hours (scenario 2).

The occurrence of kinetic restrictions that would avoid or delay their adsorption in the porosity of the carbons (scenario 1) cannot be disregarded if carbon/UV light interactions are not discarded. These interactions would appear at carbon/solution interface, and could have a 
negative effect on the accessibility of the photo-oxidation sub-products to the carbons porosity (scenario 1) or could promote the decomposition and perhaps partial mineralization of the adsorbed compounds (scenario 3).

Based on conventional wisdom, it is hard to believe that UV light could penetrate inside the porosity of strong absorbers as carbon materials. However, herein proposed scenario 3 can also be possible if the carbon/UV light interactions occur at the carbon surface promoting the photo-generation of charge carriers (likely electron-hole pairs) that could migrate through the graphitic sheets in the carbons and then be transferred to the adsorbed compounds. Moreover, the oxygen functionalities decorating the edges of the graphene layers (carbon $\mathrm{CV}$ ) could act as charge injectors upon UV excitation, or stabilize the photo-generated charge carriers (minimizing recombination).

To demonstrate if the UV light can somehow interact with the compounds retained inside the porosity of the carbon materials and thus promote the photo-oxidation of the adsorbed fraction, the reactions occurring inside the carbonaceous matrix were investigated.

\subsection{Phenol photodegradation inside the carbonaceous matrix: pre-loaded carbons}

To discriminate the catalytic activity inside carbon materials without considering the effects of adsorption kinetics and solution photolysis, irradiation was performed on carbon samples pre-loaded with phenol. Details are addressed on the experimental section; briefly the selected activated carbons were put in contact with a phenol solution and once no phenol was detected in the aqueous solution, UV irradiation was applied. First of all, it should be mentioned that after irradiation of the pre-adsorbed carbons, no desorption (leaching out) of phenol itself or any other compound was detected in the aqueous solution (confirming that above-mentioned scenario 2 does not occur). This is important as it guarantees that photolysis of phenol or its degradation intermediates do not take place. For these experiments, a high carbon:phenol ratio 
was used to ensure that all phenol is adsorbed on the carbons and that nothing remained in solution (avoiding photolysis). Thus, due to the low amount of phenol loaded on the activated carbons, the irradiation time was set to 20 minutes.

To determine the extent of phenol photodegradation (if any) inside the carbons, the samples were extracted in ethanol and the extracts were analyzed. Figure 5 shows the obtained results for the different preloaded carbons. It can be clearly seen that, with the exception of carbon PC, varied amounts of phenol and its photo-oxidation intermediates were detected in the extracts. Since no leaching out of any compound was detected for any carbon at any time, these results unambiguously demonstrate that the phenol adsorbed inside the carbons porosity is decomposed only when the activated carbons are exposed to UV irradiation.

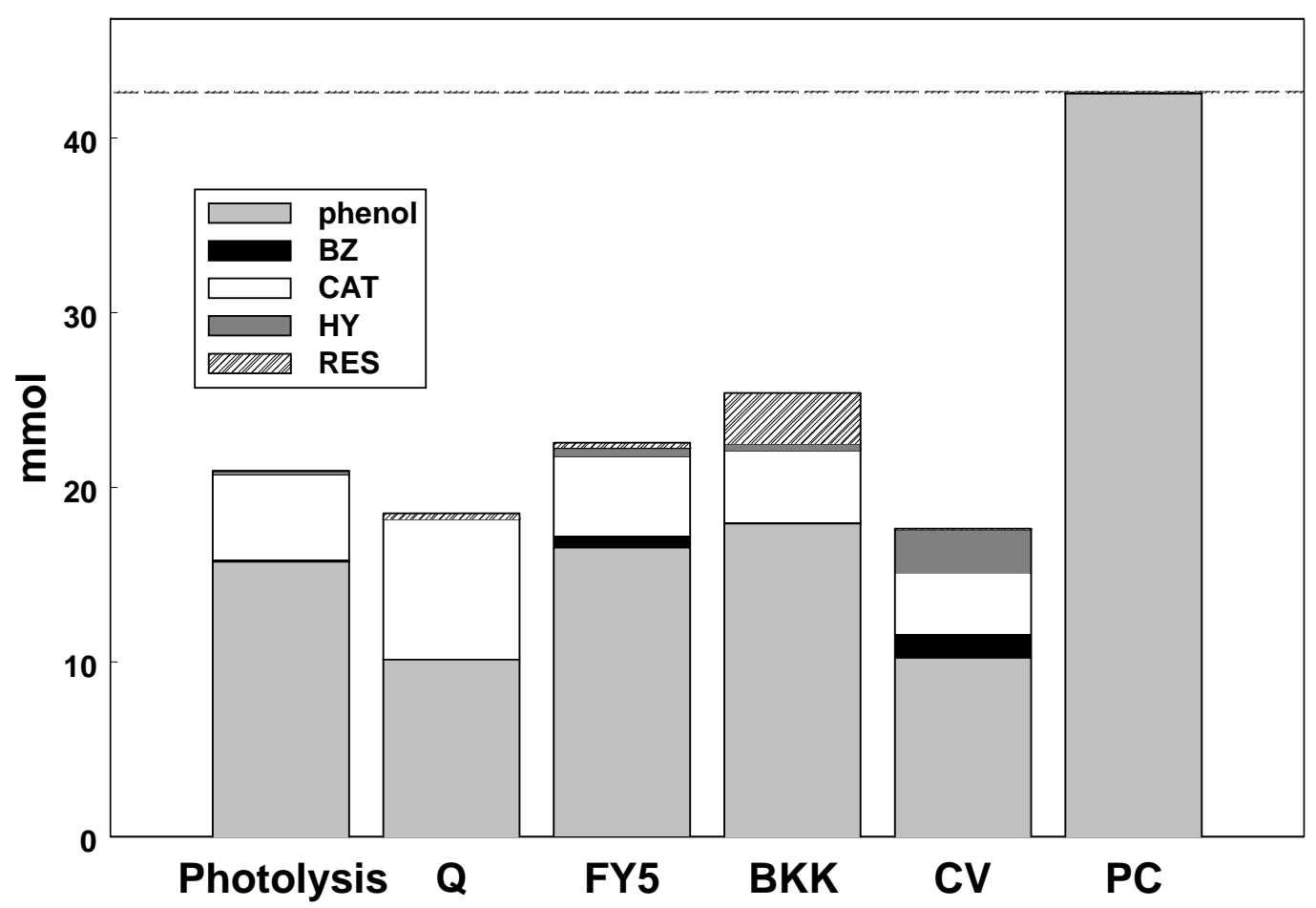

Figure 5. Quantification of the species detected in the extracts of the pre-loaded carbons after UV irradiation during 20 minutes. The dotted line represents the initial amount of phenol pre-loaded in the carbons. 
Only the phenol adsorbed on carbon PC was not decomposed, which indicates that this singular photocatalytic behaviour does not apply for all type of carbon materials, but it is somehow related to their physicochemical and/or structural features. Earlier works in the literature have also reported a non photoactive behaviour of activated carbons $[15,39]$. Unfortunately, we do not fully understand yet the relationship between the nature of the carbons and their photocatalytic activity under UV. In fact, the ash content of the studied carbons is not negligible (except for PC which ash content is zero), for which a contribution of the mineral matter cannot be discarded. However, preliminary data on de-ashed carbons (sample Q) have shown that although the photochemical yield decreased when the ash was removed, photo-oxidation of phenol still occurs for demineralised carbons. The issue of the effect of the mineral matter remains currently under investigation in our group, and it will be the object of upcoming studies.

On the other hand, the highest phenol photo-oxidation was found for carbon Q and CV, which have completely different chemical and structural properties as shown in Table 1 and Figure 1 (ca. basic and acidic nature, respectively). It is also interesting to remark that for all the carbons (but PC), phenol photodegradation was larger or similar than in the photolytic reaction (using the same phenol initial concentration). This is most remarkable since the incident photo flux arriving at the phenol molecules adsorbed inside the carbons porosity is expected to be smaller than that from solution (see discussion above). In this regard, the experiments on the pre-loaded samples enabled to estimate an apparent or pseudo quantum yield $\left(\phi_{\mathrm{ps}}\right)$ to compare with photolysis. As above mentioned, in the presence of the activated carbons the photochemical efficiency cannot be stricto sensu considered a quantum yield due to the difficulties in evaluating the fraction of light absorbed by the carbon (i.e., the accurate incident flux over the adsorbed phenol molecules). As an approximation, the pseudo quantum yield has been estimated assuming that all photons are absorbed by phenol (disregarding light 
absorption by the black catalyst). This $\phi_{\mathrm{ps}}$ value would account for the minimim limit of the actual quantum yield, allowing the comparison of the different carbons. Under these conditions, the retrieved $\phi_{\mathrm{ps}}$ values for samples Q and CV were higher (ca. 1.5 times) than that of photolysis, whereas the pseudo quantum yields of samples FY5 and BKK was similar to the photolytic reaction.

The nature of the intermediates detected was also different for the studied carbons, which confirms the role of the carbon matrix on the photocatalytic degradation pathway; for instance resorcinol (RES) was also detected in the extracts of carbons BKK, Q and FY5. Still there is no clear correlation between the photochemical response of the carbons towards phenol degradation and their physico-chemical features. Large amounts of CAT were obtained for the basic carbons (with the exception of sample PC), whereas the concentration of BZ and HY increased for the acidic CV carbon.

Anyhow, these results do not demonstrate whether if the UV light penetrates inside the carbons porosity or if carbon-photons interactions occur at the external carbon surface being subsequently propagated through the graphene sheets. Although most research is needed to further comprehend this photochemical behaviour observed in certain carbon materials, at this stage the most likely mechanism could be as follows. When the carbon is illuminated under UV light, a fraction of the incident photon flux would provoke the generation of charge carriers, which will diffuse randomly through the graphene sheets. The role of the graphitic sheets of carbons would be of paramount importance for the migration of the photogenerated electrons, minimizing recombination and favouring the electron transfer to the adsorbed molecules (phenol, water). The incorporation of oxygen-containing functionalities on the edges of the graphene sheets (the case of carbon CV) does not seem to have a negative effect on the photodegradation yield. Surface functionalities are known to withdraw electron density from the graphene sheets, although in this case, these groups could act either as charge 
injectors upon UV excitation, or stabilize the photo-generated charge carriers (minimizing recombination). All these hypotheses currently remain under investigation. These photogenerated carriers seem to have enough redox potential to generate more reactive species $\left(\cdot \mathrm{OH}, \mathrm{O}_{2}{ }^{2-}\right)$ and/or directly oxidize phenol. The formation of hydroxyl radicals $(\bullet \mathrm{OH})$ can be expected as water is simultaneously co-entrapped in the porosity associated to phenol molecules during the pre-adsorption step [28]. The occurrence of superoxide anions $\left(\mathrm{O}_{2}{ }^{2-}\right)$ can also be suspected as the overall photo-oxidation yield was reduced under oxygen-free conditions (for both photolysis and carbon catalysed reactions). Analogous photon-induced charge carrier generation has been reported for single wall carbon nanotubes [39]. Also, generation of $\cdot \mathrm{OH}$ radicals by microwave irradiation $\left(\right.$ ca. $\left.10^{-3} \mathrm{eV}\right)$ of aqueous solutions has been reported in the presence of activated carbons [40].

These results are most outstanding bearing in mind that activated carbon is the most widely used adsorbent for wastewater remediation based on adsorption technology. The possibility of carrying out in-situ degradation of pollutants on loaded carbon materials without the need of semiconductor additives offers an interesting opportunity to couple advanced oxidation techniques (for the degradation of refractory pollutants) with classic and highly skilled adsorption technologies.

\section{CONCLUSIONS}

Heretofore, carbon materials have been mainly used as supports of the photoactive species in the catalytic degradation of pollutants, and the synergistic effect observed in carbon-supported catalysts has been linked to the decrease in the recombination rate of the hole/electrons pair generated in the semiconductor (typically $\mathrm{TiO}_{2}$ ) when immobilized. In this work we have investigated the photochemical behaviour of a series of activated carbons with varied 
physicochemical features under UV light towards phenol degradation. An improved photodegradation yield was obtained when the activated carbons themselves are used as catalysts, suggesting the ability of carbon materials to promote the photo-oxidation of organic pollutants in the absence of semiconductor additives.

To further investigate this finding, the photocatalytic reaction was followed from inside the carbonaceous matrix. This allows the effects of i) the photolytic breakdown from solution and ii) the confinement due to adsorption in the porosity of the activated carbons to be disregarded. Under this viewpoint, the photochemical quantum yield of several activated carbons was higher than that of photolysis under similar conditions; the nature of the degradation intermediates was also modified in the presence of the carbon materials. Moreover, the degradation of the adsorbed fraction retained inside the pore structure of the carbons has been demonstrated. Our results suggest the occurrence of carbon-photons interactions which could be propagated through the graphene sheets of the materials, and could reach the adsorbed molecules inside the porosity.

Although more efforts are needed to further comprehend the photocatalytic mechanism which is taking place in carbon materials, we believe this work marks a starting point for further research in this field.

\section{ACKNOWLEDGMENTS}

The authors thank the financial support of projects CTM2008/01956 and HP2007/0122. LFV thanks CSIC for her predoctoral fellowship. COA thanks Dr. Vix (IS2M-CNRS) for kindly providing the TPD-MS.

\section{REFERENCES}

[1] Ollis DF, Al-Ekabi H. Photocatalytic purification and treatment of water and air. Amsterdam: Elsevier; 1993. 
[2] Pelizzetti E, Serpone N. Photocatalysis: fundamental and applications. New York: Wiley; 1989.

[3] Cunningham J, Al-Sayyed G, Srijaranai S. Aquatic and surface photochemistry. In: Helz GR, Zepp RG, Crosby DG, editors. Boca Raton, Florida: Lewis Pub; 1994, p. 317-348.

[4] Choi H, Stathatos E, Dionysiou D. Sol-gel preparation of mesoporous photocatalytic $\mathrm{TiO}_{2}$ films and $\mathrm{TiO}_{2} / \mathrm{Al}_{2} \mathrm{O}_{3}$ composite membranes for environmental applications. Appl Catal B $2006 ; 63: 60-7$.

[5] Mohseni M. Gas phase trichloroethylene (TCE) photooxidation and byproduct formation: photolysis vs. titania/silica based photocatalysis. Chemosphere 2005; 59:335-42.

[6] Erdeia L, Arecrachakula N, Vigneswaran S. A combined photocatalytic slurry reactorimmersed membrane module system for advanced wastewater treatment. Sep Purif Technol $2008 ; 62: 382-8$

[7] Sunada F, Heller A. Effects of water, salt water, and silicone overcoating of the $\mathrm{TiO}_{2}$ photocatalyst on the rates and products of photocatalytic oxidation of liquid 3-octanol and 3octanone. Environ Sci Technol 1998; 32:282-6.

[8] Fernández A, Lassaletta G, Jiménez VM, Justo A, González-Elipe AR, Herrmann JM, Tahiri H, Ait-Ichou Y. Preparation and characterization of $\mathrm{TiO}_{2}$ photocatalysts supported on various rigid supports (glass, quartz and stainless steel). Comparative studies of photocatalytic activity in water purification. Appl Catal B: Environ 1995; 7:49-63.

[9] Tryba $\mathrm{B}$, Morawski AW, Inagaki M. Application of $\mathrm{TiO}_{2}$-mounted activated carbon to the removal of phenol from water. Appl Catal B 2003; 41:427-33.

[10] Toyoda M, Nanbu Y, Kito T, Hirano M, Inagaki M. Preparation and performance of anatase-loaded porous carbons for water purification. Desalination 2003; 159:273-82.

[11] Leary R, Westwood A. Carbonaceous nanomaterials for the enhancement of $\mathrm{TiO}_{2}$ photocatalysis. Carbon 2011; 49(3):741-72. 
[12] Puma GL, Bono A, Krishnaiah D, Collin JG. Preparation of titanium dioxide photocatalyst loaded onto activated carbon support using chemical vapor deposition: a review paper. J Hazard Mater 2008; 157:209-19.

[13] Keller N, Rebmann G, Barraud E, Zahraa O, Keller V. Macroscopic carbon nanofibers for use as photocatalyst support. Catal. Today 2005; 101:323-9.

[14] Torimoto T, Ito S, Kuwabata S, Yoneyama H. Effects of adsorbents used as supports for titanium dioxide loading on photocatalytic degradation of propyzamide. Environ Sci Technol $1996 ; 30(4): 1275-81$.

[15] Matos J, Laine J, Herrmann JM. Synergy effect in the photocatalytic degradation of phenol on a suspended mixture of titania and activated carbon. Appl Catal B Environ 1998; 18: $281-91$.

[16] Araña J, Doña-Rodríguez JM, Tello Rendón E, Garriga i Cabo C, González-Díaz O, Herrera-Melián JA, Pérez-Peña J, Colón G, Navío JA. $\mathrm{TiO}_{2}$ activation by using activated carbon as a support. Part I. Surface characterisation and decantability study Appl Catal B: Environ 2003; 44:161-72.

[17] Zhang X, Zhou M, Lei $\mathrm{L} \mathrm{TiO}_{2}$ photocatalyst deposition by MOCVD on activated carbon. Carbon 2006; 44:325-33.

[18] Silva CG, Wang W, Faria JL. Photocatalytic and photochemical degradation of mono-, di- and tri-azo dyes in aqueous solution under UV irradiation. J Photochem Photobiol A: Chem 2006; 181:314-24.

[19] Takeda N, Iwata N, Torimoto T, Yoneyama H. Influence of carbon blacks as an adsorbent used in photocatalyst films on photodegradation behaviors of propyzamide. J Catal $1998 ; 177: 240-46$

[20] Velasco LF, Parra JB, Ania CO. Role of activated carbon features on the photocatalytic degradation of phenol. Appl Surf Sci 2010; 256:5254-8. 
[21] Parra JB, Ania CO, Arenillas A, Rubiera F, Palacios JM, Pis JJ. Textural development and hydrogen adsorption of carbon ma- terials from PET waste. J Alloys Compd 2004; 379(12):280-9.

[22] Kuhn HK, Braslavsky SE, Schmidt R. Chemical actinometry (IUPAC technical report). Pure Appl Chem 2004; 76:2105-46.

[23] Braslavsky SE, Glossary of terms used in photochemistry, 3rd edition (IUPAC Recommendations 2006), Pure Appl. Chem., 79 (2007) 293-465.

[24] Sing KSW, Everett DH, Haul RAW, Moscou L, Pierotti RA, Rouquerol J, Siemieniewska T. Reporting physisorption data for gas solid systems with special reference to the determination of surface-area and porosity (recommendations 1984). Pure Appl Chem $1985 ; 57: 603-619$

[25] Figueiredo JL, Pereira MFR, Freitas MMA, Órfão JJM. Modification of the surface chemistry of activated carbons. Carbon 1999; 37 (9):1379-89.

[26] Kyotani T, Karasawa S, Tomita A. A TPD study of coal chars in relation to the catalysis of mineral matter. Fuel 1986; 65:1466-9.

[27] Radovic LR, Moreno-Castilla C, Rivera-Utrilla J. Carbon materials as adsorbents in aqueous solutions. In: Radovic LR, editor. Chemistry and Physics of Carbon. New York: Marcel Dekker; 2000, p. 227-405.

[28] Velasco LF, Ania CO. Understanding phenol adsorption mechanisms on activated carbons. Adsorpt 2011; 17:247-54.

[29] Ania CO, Parra JB, Pis JJ. Effect of texture and surface chemistry on adsorptive capacities of activated carbons for phenolic compounds removal. Fuel Proc Technol 2002; 77$78: 337-43$.

[30] Gonzalez MG, Oliveros E, Wörner M, Braun AM. Vacuum ultraviolet photolysis of aqueous reaction systems. J Photoch Photobio C 2004; 5(3):225-46. 
[31] Gimeno O, Carbajo M, Beltrán FJ, Rivas FJ. Phenol and substituted phenols AOPs remediation. J Hazard Mater 2005; 119(1-3):99-108.

[32] Rodríguez M, Abderrazik NB, Contreras S, Chamarro E, Gimenez J, Esplugas S. Iron (III) photoxidation of organic compounds in aqueous solutions. Appl Catal B: Environ 2002; $37: 131-7$.

[33] Kusic H, Koprivanac N, Bozic AL, Selanec I. Photo-assisted Fenton type processes for the degradation of phenol: a kinetic study. J Hazard Mater 2006; 136(3):632-644.

[34] Santos A, Yustos P, Quintanilla A, Garcia-Ochoa F. Kinetic model of wet oxidation of phenol at basic pH using a copper catalyst. Chem Eng Sci 2005; 60:4866-78.

[35] Santos A, Yustos P, Quintanilla A, Rodríguez S, Garcia-Ochoa F. Route of the catalytic oxidation of phenol in aqueous phase. Appl Catal B: Environ 2002; 39:97-113.

[36] Mijangos F, Diaz M. Kinetic analysis of a bimetallic ion exchange system by microscopic measurement of the moving boundaries. J Col Interf Sci 1994; 164:215-222.

[37] Mijangos F, Navarro A, Jodra Y. Kinetic analysis of phenol adsorption from aqueous systems. Can J Chem Eng 2001; 79:737-43.

[38] Lee CYC, Pedram EO, Hines AL. Adsorption of oxalic, malonic and succinic acids on activated carbon. J Chem Eng Data 1986; 31:133-6.

[39] Matos J, Chovelon JM, Cordero T, Ferronato C, Influence of Surface Properties of Activated Carbon on Photocatalytic Activity of $\mathrm{TiO}_{2}$ in 4-chlorophenol Degradation. The Open Environ. Eng. J. 2009;2:21-29.

[40] Lu S, Panchapakesan B. Photoconductivity in single wall carbon nanotube sheets. Nanotechnology 2006; 17:1843-50.

[41] Quan X, Zhang Y, Chen S, Zhao Y, Yang F. Generation of hydroxyl radical in aqueous solution by microwave energy using activated carbon as catalyst and its potential in removal of persistent organic substances. Molec Catal A: Chem 2007; 263:216-22. 